\title{
PRESENTACION
}

Eric Hobsbawm, uno de los más brillantes historiadores del siglo $\mathrm{XX}$, respondía de la siguiente manera a una pregunta formulada por Antonio Polito a propósito de los vertiginosos cambios acaecidos en la sociedad durante los últimos diez años del siglo $\mathrm{XX}$, y si ellos habrían contribuido a ser más felices a los seres humanos: "Esta es una de las preguntas más difíciles de responder, y rio sólo para un historiador, sino para cualquier observador contemporáneo. Lo único que sabemos es que lo que Jefferson llamó 'la búsqueda de la felicidad' es una motivación general de los seres humanos, por lo menos en los tiempos modernos. Hasta qué punto esta aspiración llega a materializarse es algo muy difícil de establecer". (Eric Hobsbawm, Entrevista sobre el siglo XXI. Barcelona, Crítica, mayo de 2000, p. 143). Esa aspiración, a la que hacía referencia Hobsbawm, no ha sido una tarea fácil a lo largo de los tiempos, por el contrario ha estado plagada de conflictos, sufrimientos y sacrificios de los hombres y mujeres del ayer, del pasado que todavía pervive en muchas facetas de nuestra sociedad actual en forma de traumas no superados. Y es precisamente la historia y el historiador comprometidos con unos ideales de vida digna, quienes también tienen mucho que decir y aportar en esta búsqueda de la felicidad y del bienestar social. Es, por decirlo de alguna manera, un compromiso cívico y una responsabilidad moral del historiador. Compromiso y responsabilidad que van más allá de los meros conocimientos que se enseñan en las aulas de clase y la oficina; es pensar a Colombia en la actual encrucijada, es comprender un trauma social de larga duración basado en exclusiones y negaciones del pluralismo disfrazados de armonía social, en una Colombia que reclama a gritos el fortalecimiento de la democracia 
y la consolidación de una verdadera sociedad civil. Quisiéramos terminar esta parte de la reflexión referida al compromiso social del historiador y de la historia, con una contundente afirmación de Joseph Fontana, que creemos no solamente válida para los historiadores sino para los intelectuales en general en Colombia: "El historiador en este país debe tener una conciencia muy clara de que su trabajo no es una cultura decorativa para entender a la gente sino que está tratando de responder a preguntas cruciales de la sociedad. Esto debe dar una vitalidad a la historiografía colombiana" ("Historiay compromiso cívico". Entrevista a Joseph Fontana. Guiada por Alfonso Torres Carrillo. Memoria y Sociedad, 1, Pontificia Universidad Javeriana, 1995, pp. 17-25).

Este segundo número de El Taller de la Historia ofrece a la comunidad académica variados trabajos, tres de ellos presentados en el IV Seminario de Historia del Caribe Colombiano, realizado por la Universidad de Cartagena a través de la Facultad de Ciencias Humanas y el Programa de Historia, en asocio con otras instituciones como el Banco de la República, el Observatorio del Caribe y el Instituto Distrital de Cultura, entre el 29 de mayo y el $1^{\mathrm{O}}$ de junio de 2001. Los dos primeros trabajos que aparecen se enfocan hacia fenómenos sociales rurales del Caribe colombiano y venezolano. En un primer artículo, Marta Herrera Ángel estudia y analiza un fenómeno en las llanuras de la costa Caribe colombiana a mediados del siglo XVIII: el arrochelamiento. Plantea la autora que la generalización y uso del concepto de arrochelamiento no se debió al surgimiento de prácticas que se alejaban del orden establecido por el Estado colonial, sino en el interés de las autoridades y ciertos sectores dominantes de la sociedad caribeña por ejercer un efectivo control sobre estos pobladores. Posteriormente, la historiadora y profesora de la Universidad del Zulia, Carmen Laura Paz, nos introduce en la sociedad wayúu de mediados del siglo XIX, mostrando una línea de continuidad en las estrategias de resistencia de este grupo aborigen, basadas fundamentalmente en los principios consuetudinarios del derecho. El foco espacial en que se centra la autora es la Guajira venezolana. 
Posteriormente, Adriana Santos, en una línea de trabajo que media entre la historia de la educación y las estrategias pedagógicas por parte del establecimiento para impulsar la creación de valores políticos, muestra cómo los periódicos, pasquines, cartillas y hojas volantes no solamente se trazaron como meta la educación de los ciudadanos en el plano de los principios liberales o conservadores, sino que sirvieron, además, para divulgar las propuestas de la élite política nacional y regional.

El profesor Wilson Blanco Romero, siguiendo con una línea de trabajo sobre la historia socioeconómica de la provincia de El Carmen de Bolívar, enmarcada en la producción tabacalera, nos ofrece en esta oportunidad una reflexión sobre la presencia extranjera y su influencia en la vida económica y empresarial de la región "Montemariana", concretamente el caso de los Volpe.

Finalmente, aparece un trabajo que se centra en la reflexión teórica y metodológica de la disciplina histórica a finales del milenio y los consabidos cambios que han transformado el panorama político, social y cultural del mundo. En efecto, Carlos Barros, de la Universidad de Santiago de Compostela, reflexiona sobre la legitimidad de la historia ante tales transformaciones y propone, como salida a la llamada "crisis disciplinar", la creación de un nuevo paradigma. Precisamente, la creación de un nuevo paradigma como salida de la crisis es la propuesta de Historia a Debate, espacio de reflexión y polémica donde se dan cita historiadores de todos los rincones del mundo a través de la red www.h-debate.com. En esta oportunidad, hemos incluido en la revista tal propuesta bajo el título de Manifiesto Historiográfico de Historia a Debate, en la sección documental.

Terminando las secciones de la revista se encuentran las reseñas de importantes trabajos de historia publicados entre 1999 y 2001.

Queremos agradecer a la doctora Sonia Burgos Cantor, decana de la Facultad de Ciencias Humanas, su apoyo permanente en 
XEL I ALLEK DE LA HISIURIA 2

la consolidación de El Taller de la Historia. A nuestros colaboradores y patrocinadores nuestro más sentido respeto y agradecimiento. Queda, pues, a consideración de la crítica de la comunidad académica este segundo número de la revista. Gracias.

\section{LA DIRECCIÓN}

